\title{
Bringing access and benefit sharing into the digital age
}

\author{
Sylvain Aubry, ${ }^{1,2}$ (D) Christine Frison ${ }^{3,4}$ (D) | Jorge C. Medaglia ${ }^{5}$ | Emile Frison ${ }^{6}$ (D) | \\ Marcel Jaspars ${ }^{7}$ (D) | Muriel Rabone ${ }^{8}$ (D) | Aysegul Sirakaya ${ }^{9}$ (D) | Devanshi Saxena ${ }^{3}$ (D) | \\ Esther van Zimmeren ${ }^{3}$
}

\author{
${ }^{1}$ Federal Office for Agriculture, Bern, \\ Switzerland \\ ${ }^{2}$ Department of Plant and Microbial Biology, \\ University of Zürich, Zürich, Switzerland \\ ${ }^{3}$ Government and Law Research Group, \\ University of Antwerp, Antwerp, Belgium \\ ${ }^{4}$ F.R.S-FNRS, University of Louvain, \\ Louvain-la-Neuve, Belgium \\ ${ }^{5}$ University of Costa Rica, San Pedro, Costa \\ Rica \\ ${ }^{6}$ Alliance of Bioversity International and \\ CIAT, Maccarese, Italy \\ ${ }^{7}$ Marine Biodiscovery Centre, Department \\ of Chemistry, University of Aberdeen, \\ Aberdeen, UK \\ ${ }^{8}$ Life Sciences Department, Natural History \\ Museum, London, UK \\ ${ }^{9}$ Faculty of Law, University of Ghent, Ghent, \\ Belgium
}

\section{Correspondence}

Sylvain Aubry, Department of Plant and Microbial Biology, Zürich, Switzerland. Email: sylvain.aubry@botinst.uzh.ch

Christine Frison, F.R.S-FNRS, University of Louvain, Louvain-la-Neuve, Belgium. Email: christine.frison@uclouvain.be

Funding information Research Foundation (FWO) Flanders, Grant/Award Number: 12X8318N; Swiss National Science Foundation, Grant/Award Number: 31003A_172977

\section{Societal Impact Statement}

Reading and writing DNA is now possible with an unprecedented speed and ease. To catch up with digitization of genetic resources, scientists need to join with all relevant stakeholders and design new global governance mechanisms for digital sequence information. We propose the establishment of a Multi-stakeholder Committee on the Governance of Digital Sequence Information (DSI). This multi-disciplinary body will be dedicated to mitigate governance issues associated with the digitization of genetic resources. Solving the DSI conundrum is sorely needed given the forthcoming multilateral meetings of the Access and Benefit Sharing (ABS) framework (the next CBD COP is scheduled in 2021) that are central to tackle the global loss of biodiversity, global warming, pandemic risk and food insecurity.

\section{Summary}

Contemporary research is increasingly data- centric and the rise of genomics revolutionized our approach and use of genetic resources. However, genomics developed relatively independently from the international instruments on the conservation of biological diversity, in particular the Access and Benefit Sharing (ABS) framework. The legal and political status of Digital Sequence Information (DSI) derived from genetic resources emerged recently as a contentious point in the various ABS instruments dealing with genetic resources. In view of the multiple parallel and uncoordinated debates that occurred in various forums dealing with plants, animals, terrestrial, microbial, marine and agricultural biodiversity, we propose here to take a step back in the discussion. We argue that DSI should be considered as an overarching issue to be addressed through a coordinated and inclusive Multi-stakeholder Committee that would assess its position and role within the existing ABS regime complex. This Multi-stakeholder Committee on the Governance of Digital Sequence Information, that may run under the auspices of the United Nations, will be dedicated to mitigate global governance issues associated with the digitization of genetic resources. In this paper, we sketch this body as a transversal and inclusive tool to facilitate long-term coherence in all ABS policy forums. 


\section{KEYWORDS}

access and benefit sharing, biodiversity, committee, Digital Sequence Information (DSI), genomics, plant genetic resources, Plant Genetic Resources for Food and Agriculture (PGRFA)

\section{1 | INTRODUCTION}

With several terabases of sequence data produced annually worldwide (Stephens et al., 2015), digitization of genetic resources has emerged as a central issue in all international forums concerned. Numerous debates have occurred around digitization of genetic resources and derived digital sequence information (DSI). DSI is a placeholder term first used in 2016 in the Convention on Biological Diversity (CBD) negotiations. It has also later been used in other international legally binding instruments that constitute the Access and Benefit Sharing (ABS) regime complex. The ABS framework is aiming at the conservation of biological diversity and regulates access to genetic resources through "the sustainable use of (Biological diversity) components and the equitable sharing of benefits arising from the utilization of genetic resources" (article 2 of the Convention on Biological Diversity; CBD, 1992). It consists of several independent and specialized instruments: the $\mathrm{CBD}$, the International Treaty for Plant Genetic Resources for Food and Agriculture (ITPGRFA, 2004, also referred to as the Plant Treaty), the Pandemic Influenza Preparedness (PIP) framework, the Antarctic Treaty (AT) and the Biodiversity Beyond National Jurisdiction negotiations under the auspices of the United Nation Convention on the Law of the Sea (UNCLOS; Oberthür \& Pożarowska, 2013; Figure 1). The rise of highthroughput omics techniques and the increased ability to sequence and synthesize DNA have gradually diffused rather inconsistently into these various forums.

Considering the primary objectives of the CBD and the $A B S$ framework, it seemed logical to embrace "genetic resources" very much as a "holistic" concept. The recent controversy created between the physical/material component of the genetic resource (mostly reproductive material) and the digital/immaterial component therein contained (genetic sequence data and information) may very much lie in the rise and promise of sequencing globally (Halewood et al., 2018; Lewin et al., 2018) and the "datafication" of genomics (Stephens et al., 2015). This controversy has raised doubts on the efficiency and effectiveness of the ABS framework in reaching its objectives and highlighted its fragilities (Frison, 2018; Laird et al., 2020). DSI may generally, but not strictly, be considered as genomic data and the debates on DSI fluctuate from exclusively considering nucleotide sequences (generally referred to as genetic sequence data) through to extended associated information (e.g. traditional knowledge or meta-data) linked to genetic resources (Aubry, 2019; Cabrera Medaglia, 2020; CBD, 2019). Recent reports commissioned by the CBD and the CGRFA suggested defining the scope as "molecular" data (i.e. DNA, RNA, proteins and metabolites) but no real consensus on the definition exists (CBD, 2019). While the ongoing discussions on DSI governance in ABS instruments have shown considerable tensions (Laird et al., 2020), consensual solutions have not

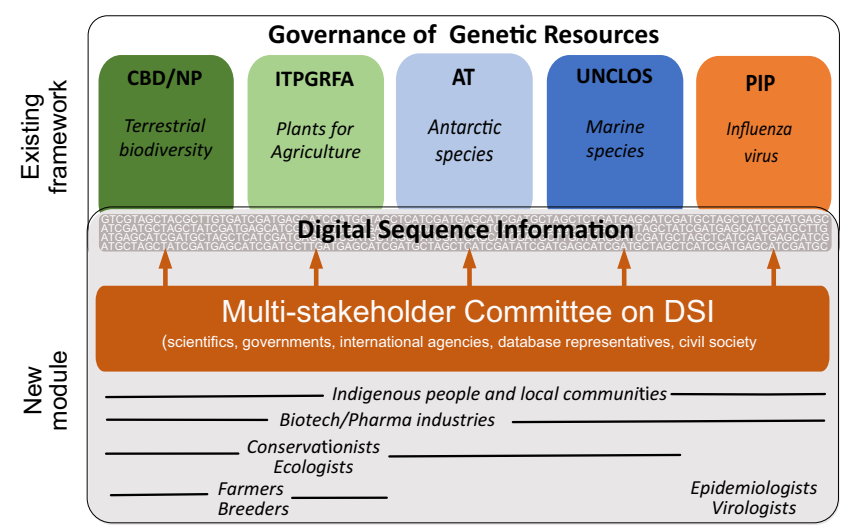

FIGURE 1 A Multi-stakeholder Committee will promote coherence throughout the ABS instruments over digitization. DSI is considered here as an overarching object to be treated as a "transversal" issue. A Multi-stakeholder Committee on DSI would re-assess and design the current ABS framework aiming at a coherent and inclusive approach for DSI. This committee would allow for close collaboration with multiple stakeholders including the major genomic database consortia as well as farmers or local and indigenous communities who play a key role in biodiversity conservation, development and sustainable use and, most importantly, facilitate a coherent approach to the diverse instruments dealing with DSI. This would, in turn, allow each instrument to focus on their respective primary aims including: conservation of biodiversity for CBD, AT and UNCLOS, food security for the ITPGRFA, public health for PIP. CBD, Convention for Biodiversity; NP, Nagoya Protocol; ITPGRFA, International Treaty for Plant Genetic Resources for Food and Agriculture; PIP, Pandemic Influenza Preparedness; UNCLOS, United Nation Convention on the Law of the Sea; AT, Antarctic Treaty

yet emerged to maintain the flow of benefits from commercial exploitation of genetic resources. Several stakeholders argue that the exponential digitization of genetic data might further degrade this situation. Despite the generally well-recognized importance of open access, an elusive promise of some indirect economic incentive (e.g. capacity building or technology transfer) as a compensation for free access to DSI is unlikely to persuade most stakeholders at play, especially conservationists, farmers as well as indigenous people and local communities (Bond \& Scott, 2020; Laird et al., 2020). It could also be argued that an emphasis on economic incentives has derailed much of the debates on genetic resources away from conservation and towards an excessive focus on commercialization.

Beyond the "technical" debate on collection, access and use of DSI lies a wider vision of the role of science in global governance (Boesch, 1999) and its underlying power plays that need to be carefully considered. Global governance is understood as "governing, without sovereign authority, relationships that transcend national frontiers" (Finkelstein, 1995:369) to "capture the complex reality of 
governance, which encompasses all the structures and processes for determining the use of available resources for the public good within a country" (Weiss, 2000). One instrument of this global governance, the ABS framework, is still broadly considered to be some of the most politically viable options for conserving biodiversity and mitigating food insecurity (Morgera, 2016, 2017; Sirakaya, 2019). However, it remains to be seen to what extent focusing mainly on the link between access to "resources" and benefits deriving from their use in the ABS model of governance is still relevant to the contemporary scientific (genomic) practice.

Adapting global genetic resources policy is therefore strongly recommended to ensure legal coherence, avoid legal fragmentation between policy areas and advance the conservation and sustainable use goals of the different instruments governing these resources. In this paper, we suggest to consider digitization of genetic resources as an overarching issue that requires a coordinated global policy approach.

\section{2 | MODALITIES OF DSI USE AND THE ABS RATIONALE IN THE PGRFA CASE}

The question of access to genetic resources has strong political and economic forces, superseding the environmental and social objectives of the CBD or the Plant Treaty (Jungcurt, 2008). The concept of ABS was designed to establish transparent and fair access rules for users to access biological diversity (mainly in low- and middle-income countries) against a fair and equitable compensation that would then be channelled into biodiversity conservation (Frison, 2021).

Parties to the CBD and its Nagoya Protocol on Access to Genetic Resources and Fair and Equitable Sharing of Benefits Arising from their Utilization (the Nagoya Protocol) have to implement national legislations-that may vary from one country to another-where fair and equitable benefits (Nagoya Protocol article 5.3) would be exchanged against access to genetic resources (Nagoya Protocol article 6.3). Benefits can be monetary (e.g. royalties, access fees, license fees) or non-monetary (e.g. capacity building activities, technology transfer, participation in research, etc.), and aim at supporting conservation in the countries receiving them (Morgera, 2016). However, in view of the growing evidence of dramatic biodiversity and agrobiodiversity losses (Belanger \& Pilling, 2019; IPBES, 2019), it is clear that the objectives of biodiversity conservation are not met, as Stoll recognized already in 2009 when he stated "[t]here is no indication that, in the 15 years since the adoption of the [CBD], the ABS system has had any significant impact on conservation, be that benefits being used to undertake certain conservation measures or halting of the human degradation of biodiversity" (Stoll, 2009). More recent literature is similarly unable to clarify why benefit sharing has not developed incentives for biodiversity conservation over the years (Lawson et al., 2018). One possible reason is the lack of a clear definition for benefit sharing under international law (Morgera, 2016), which creates misunderstanding as to what benefit sharing is and what it ought to achieve (Cabrera Medaglia \& Perron-Welch, 2019).
Notwithstanding this realization, the link created between access to genetic resources and benefit sharing necessarily means that the greater the number of accesses, the more likely larger benefits will flow back. This was the rationale back in the 1990s and is still the case today. Hence, the importance of having a robust and clear interpretation of what is or is not a genetic resource bound by ABS obligations cannot be overestimated.

Focusing briefly on the Plant Treaty case, and to answer this question under agrobiodiversity international law, a legal interpretation exercise (following the interpretation rule of the Vienna Convention on the Law of Treaties, 1980; Art. 31-33) was carried out in 2015 on the terms "plant genetic resources for food and agriculture" (PGRFA) and "genetic material" under the Plant Treaty (Frison, 2018). In article 2, PGRFA are defined as "any genetic material of plant origin of actual or potential value for food and agriculture"; and "genetic material" means "any material of plant origin, including reproductive and vegetative propagating material, containing functional units of heredity" (emphasis added). Part IV of the Plant Treaty delineates what can be accessed, under what conditions and what benefit sharing obligations derive from the access. Its article 12.3(d) states that "[r]ecipients shall not claim any intellectual property or other rights that limit the facilitated access to the plant genetic resources for food and agriculture, or their genetic parts or components, in the form received from the Multilateral System" (emphasis added). As a result, we share Frison's legal interpretation stating that genetic information (i.e. the DSI) extracted from genetic material should be included in the definition of "parts and components" of the genetic resource and that it contains "functional units of heredity" of the genetic material (Frison, 2018). Refuting this interpretation would render the whole multilateral system void. The fact that we can now extract more and better genetic information related to the genetic resources using genomics does not change the purpose of the exchange or the (material and informational) object accessed. The coded information can be used to synthesize iteratively new "functional units of heredity" that can then be utilised in research and development pipelines. Doing so, the DSI will regain physicality in an improved product (e.g. an improved variety in the frame of the Plant Treaty) to be commercialized and has no value outside of its physical shell. Not including the DSI in the definition of the genetic material is simply a means to avoid the multilateral benefit sharing provisions. This interpretation does not respect the spirit or the objectives of the Plant Treaty and it does not implement properly the principles of the Vienna Convention on the law of Treaties (Frison, 2018). Pushing this argument further, international treaty law imposes that DSI (given an agreement is found on the extent of a definition) should follow current $A B S$ rules. We do not believe that applying $A B S$ obligations to DSI would solve all the ABS-related problems and ensure sufficient money flowing back as benefit sharing. But nonetheless, such an interpretation, not setting clearly the boundaries between DSI and genetic resources, put great risks of seeing a large portion of current use legally flawed and ethically wrong. If countries want to establish a different and specific regime for DSI, separate from the current $A B S$ regime for genetic resources, they are free to do so 
and adapt, modify or create new obligations. In cases where tracing DSI back to the genetic material of origin is less feasible (e.g. for synthetic biology), benefits could be directed towards a collective fund, similar to the Plant Treaty benefit sharing fund, which then distributes the benefits back to communities for conservation and sustainable use.

\section{3 | "DIGITAL SEQUENCE INFORMATION": NEITHER NEW NOR EMERGING}

Building upon the non-consensual definition of DSI is difficult given the blurred boundaries described in the previous section. Meanwhile, there is a well-established framework in which genomic data are collected, stored and shared, notably under the International Nucleotide Sequence Data Collaboration (INSDC). It has been developed in parallel to the international instruments governing genetic resources but with little interaction between these entities until the last decade (CBD, 2019). Describing DSI as a "new and emerging issue" (CBD XIVth Convention of the Parties, 2016) reveals the tremendous lag between scientific progress, and the political debates within the ABS framework. Fears of an unprecedented wave of new type of "digital appropriation" of genetic resources have pushed the DSI issue at the forefront of political debates (CBD, 2019). Interestingly, not long after the CBD inception, the challenges of digitization were already recognized, as Pistorius and Van Wijk noted: "the collection and storage of genetic information in the form of data on DNA sequences is much more attractive than in the form of seed" (Pistorius \& van Wijk, 1999). While collecting seeds in genebanks has been instrumental in the framing of modern breeding, this practice has also been strongly criticized for surveying and centralizing the resources without necessarily integrating all stakeholders (Peres, 2016). Maybe more generally, the modalities of use of the DSI generated from genetic resources (being seeds or other genetic resources) are changing with the rise of genomics. Considering the way DSI are processed and analysed, a vast majority of the DSI wil never yield economic value. However, the potential of large-scale sequencing should not be under-estimated and will improve accessibility to data that, in turn, may increase opportunities for profit making (Deplazes-Zemp et al., 2018). The actual DSI debate for genetic resources is comparable to early policy issues that were initiated by the Human genome sequencing project some 20 years ago. Worries about the transparency, inclusiveness in this field, having obvious ethical concerns, ended up with the inception of ad hoc instruments like the Universal declaration on the Human genome and Human rights under the auspices of the UNESCO (UNESCO, 1998). There already (Human) genetic data were recognized having some "cultural significance for persons or groups" (Art. 7, UNESCO, 2003). A concept that may easily be transposed to some genetic resources regulated by the $A B S$ instrument. For example, genetic data from crops that were domesticated for thousands of years, and that would not be representing any economic or cultural value without any human intervention could be granted some kind of similar status.
In the International Declaration on Human Genetic Data (IDHGD, UNESCO, 2003), Human genetic data are defined in its Art. 2i as "[i] nformation about heritable characteristics of individuals obtained by analysis of nucleic acids or by other scientific analysis". This "agreed text" could set the basis for a more general DSI definition. In any case, genomic data (DSI) are central to modern bioscience and the way bioeconomy generates benefits (Thacker, 2005). We argue that the DSI controversy revealed existing inequalities and fragilities of the ABS framework that is constrained by underlying power relationships between states, between stakeholders, as well as to differences in scientific capacity across countries. The existing governance mechanism needs to be reassessed and redesigned urgently following ethical principles. We detail in the next section how lessons might be learnt from the history of plant genetic resources.

\section{4 | LEARNING FROM THE SEEDS}

During its eighth session in November 2019, the Governing Body of the Plant Treaty called for a change of paradigm regarding digitization of genetic resources. The Plant Treaty has a clear definition of genetic material: "any material of plant origin, including reproductive and vegetative propagating material, containing functional units of heredity" (FAO Plant Treaty, article 2). Its multilateral scope remains constrained to the 64 crop and forage species listed in its Annex I, as attempts for enlargement have failed along with efforts to finding a sustainable financing strategy. However, the Plant Treaty still constitutes a unique example of multilateral governance for a subset of genetic resources as a global common. It is a unique space recognizing the particular anthropogenic character of agrobiodiversity that laid the ground to the concept of farmer's rights at the national and international levels (Aubry, 2019; Frison, 2018). Failure to improve the benefit sharing mechanism of the Plant Treaty and its multilateral system (by enlarging the scope and establishing a subscription model) was largely due to the underlying debates questioning whether DSI is within the scope of the Plant Treaty, and therefore of its multilateral ABS system. Indirect incentives to compensate for open access to DSI were apparently not sufficient to satisfy all parties during this Plant Treaty Governing Body session (ENB, 2019). A similar blockade could happen during the ongoing Post-2020 Agenda negotiations of the CBD. The ever-growing focus on DSI diverts much effort from the overall objectives of each instrument, being the conservation of biodiversity for the CBD or food security for the Plant Treaty. Discussions on the potential development of a multilateral option for ABS under article 10 of the Nagoya Protocol might be a possible way to handle DSI, but the modalities of such a change in the scope of the protocol remain relatively unclear. None of the ABS instruments has successfully addressed digitization issues in their respective negotiation forum. Considering this failure and the related political importance, we believe it is urgent to consider DSI through a different, coordinated and overarching approach. This approach should enable to address DSI's specific features (DSI are nonstatic, widespread and non-rivalrous artefacts; Aubry, 2019), clarify 
the legal context and subsequently enhance the implementation of existing ABS instruments.

\section{5 | EQUITY IN SCIENCE AND THE DIGITAL DIVIDE}

As conservation of biodiversity and facilitated access to genetic resources are considered core objectives of the ABS instruments, providing open access to digital data originating from genetic resources could be promoted as benefit sharing by what is referred to as "equity and fairness" in science (Laird et al., 2020). This is particularly important for digital data that are widely available through multiple sources and access to which is hard to trace (CBD, 2019). However, open access is not necessarily considered fair by all actors. Actors, from North and South, do not have the same capacity to produce and benefit from scientific results generated from these data (Leonelli, 2014). The underlying inequalities in capabilities to access, analyse, use and finally publish these (big) data are likely to undermine a fair and equitable sharing of benefits. For example, uneven access to information and communication technologies in low- and middle-income countries has recently proven the limits of data-driven farming: there is no need to add a breeding divide to a digital divide (Mehrabi et al., 2020). Beyond merely agreeing on the moral value of producing open access data, a deeper discussion is needed on the extent to which the existing open access system to DSI is benefiting all stakeholders and humanity at large.

\section{6 | A NEW TRANSVERSAL GOVERNANCE OF DSI}

Not properly considering how badly the DSI controversy could damage science and global genetic resources governance, especially the CBD, its Nagoya Protocol and the Plant Treaty, may significantly harm multilateralism as a whole. In addition, the status quo allows circumventing current instruments and might encourage more jurisdictions to adopt uncoordinated measures that will not serve any of the ABS objectives (Deplazes-Zemp et al., 2018). Since the COP14, some important work has already been performed by the Ad Hoc Technical Expert Group established by the CBD, in close collaboration with the Commission on Genetic Resources for Food and Agriculture (CGRFA) that produced a comprehensive set of peer-reviewed studies framing the DSI controversy (CBD, 2019). These studies and other similar work aimed at providing details on terminology of DSI, genomic data, the state-of-the-art on traceability, databases and a description of existing domestic measures addressing that matter (CBD, 2019, Morgera et al., 2020). While this work is central to frame the current knowledge about modern genomics, no clear political way out the controversy has emerged so far. In the near future, these uncertainties may lead to fragmentation and increase the fragility of datasets if each country chooses to develop their own DSI databases. During the early days of the recent COVID-19 pandemic, there were delays and difficulties in timely sharing of viral genome sequences data between countries. This is a compelling example for the need of a more general and coordinated digital data governance (Ribeiro et al., 2018). Interestingly, the most advanced forum dealing with genomic data may be the pandemic influenza preparedness, running under the auspices of the World Health Organization (WHO, 2011). While it is restricted for the influenza virus, it provides an agreed definition for genetic sequence data and some ABS modalities that also explicitly concern data (Rourke, 2019).

We propose stepping back in the discussion and reconsider DSI as an overarching issue to be addressed through a coordinated and inclusive Multi-stakeholder Committee that would reassess its position and role within the existing $A B S$ regime complex (Figure 1). Increasing complexity of many multilateral issues led some international forums to seek external advice and create various informal groups and ad hoc committees to facilitate negotiations (Herz, 2018). The Committee addressing DSI would identify options and/or provide recommendations to adapt the various ABS frameworks to the digital age. Inspired by the functioning of the FAO Committee on World Food Security (CFS, 2017, 2020), the Multistakeholder Committee on the Governance of Digital Sequence Information would work in synergy with existing ABS instruments to better frame and respond to this common issue (De Schutter, 2013). In 2009, the CFS, under the aegis of the FAO, went through deep reform in the aftermath of the 2007-2008 food crisis, with a view to making the CFS "the most inclusive international and intergovernmental platform for all stakeholders to work together in a coordinated way to ensure food security and nutrition for all [so as] to ensure that the voices of other stakeholders were heard in the global debate on food security and nutrition" (CFS, 2017). Two elements arising from this reform are of particular interest: the establishment of the Advisory Group, accompanied by a panel of experts, and the adoption of a Global Strategic Framework. Together with the Bureau composed of member countries, the Advisory Group is a true forum for discussion bringing together representatives of the main actors in the food sector: specialized agencies and other United Nations bodies, civil society organizations, non-governmental organizations (representing in particular smallholders), international agricultural research institutions, financial institutions, representatives of the private sector and philanthropic foundations. In addition, a panel of independent experts, specialized in various issues related to food security and nutrition, facilitates discussions in the Committee's bodies through various reports prepared following dialogues with a wide range of stakeholders.

A similar functioning body could be put in place for DSI, where representatives of all stakeholder groups, that is, governments, international agencies, scientific, as well as civil society organizations and the private sector (e.g. farmers, local and indigenous communities and major database representatives) would interact. The rules to select the Committee members might be inspired by the CFS. The rules of procedures of the Committee could be designed at a joint meeting between the bureau members of all involved international instruments (mentioned above) and discussed 
for adoption at the first Committee meeting. Discussions could take place under the Chatham House rule, allowing members to talk freely in their personal capacities, thereby moving away from historical political positions. Decisions could be taken by consensus, or any other inclusive decision-making process adopted in the rules of procedures and be guided by strong ethical values (equity and fairness) and a strong commitment to ensuring that the Northern states' meet their responsibilities for biodiversity degradation. It is important for the Committee to be linked operationally to a UN institution. It may possibly be run under the auspices of the United Nation Environment Assembly (UNEA) Governing Bodies Secretariat. Indeed, the UNEA secretariat already serves an ad-hoc open-ended expert group on marine litter and microplastics (UNEA, resolution 4/6, 2019).

The Committee aims to be an inclusive facilitator and would help to:

- Enable thoughtful, transparent, independent, fair and inclusive discussions with all involved stakeholders.

- Feed governing bodies and conference of the parties of existing international ABS instruments with overarching, coordinated and coherent advice/opinions on how to handle the DSI question.

- The Committee's mandate should be determined by the Committee itself with the widest/most inclusive mindset possible but might include:

- Drawing the boundaries of a universally agreed definition of DSI that can define the scope of future debates. A possible leap forward into developing open access would be to consider the pool of genomic data as global commons (Hess \& Ostrom, 2003).

- Addressing the urgent necessity to finance biodiversity conservation and capacity building for sustainable use, by exploring, inter alia, available options around possible new taxation schemes for the commercial applications of DSI to fund existing benefit sharing funding mechanisms.

- Possibly assisting the drafting of a new legally binding instrument that takes DSI explicitly into consideration. Even if this option may raise some eyebrows among experts, ongoing negotiations on marine biodiversity beyond national jurisdiction are concentrating on a new instrument where this matter is of importance (Blasiak et al., 2020). For marine genetic resources, it has been suggested to subject both material and digital resources to benefit sharing obligations but following distinct modalities (Humphries et al., 2020). The existence of the various ongoing parallel processes, such as in marine, agricultural and medical domains, provides a strong argument for a transversal approach to solve this controversy.

By supporting existing country-led processes in the various negotiation forums, the Committee would provide a coordinated and coherent approach to the diverse ABS instruments dealing with DSI, aiming at enhancing fair and equitable implementation, efficiency and effectiveness of related international obligations. Care would be taken to safeguard coherence between all instruments that deal with genetic resources, since there are strong ethical and legal arguments that bind the way material and immaterial (DSI) aspects of genetic resources are addressed (Frison, 2018). Normalizing access to and use of DSI for all players may ease protracted discussions in the forthcoming ABS negotiations.

Indeed, the major reason why DSI troubles the ABS negotiation forums so much relates to benefit sharing, which is primarily supposed to enable biodiversity conservation and capacity building for sustainable use. However, the low levels of monetary and non-monetary benefits that are shared under the CBD and the Plant Treaty are insufficient to reach their respective objectives, which is repeatedly stated by countries from the Global South (CBD, 2019). It is essential for the Committee to be effective, that all parties realize the systemic influence of digitization in this field: DSI is a game-changer that enables a complete re-thinking of the entire ABS framework. All ABS instruments seek options for enhancing and securing sustainable funding. Interestingly, a recent effort from a European-based consortium (Wissenschaftsbasierte Lösungsansätze für Digitale Sequenzinformation, WiLDSI) proposed a number of policy options for ABS and DSI while safeguarding open-access (WILDSI, 2020) proceeding from a scientific perspective. This initiative will hopefully provide a valuable basis for future negotiations. However, this consortium may not always succeed in reflecting all possible concerns and sensibilities. It is therefore essential that inclusiveness, as inspired by the CFS example described above, remains one of the main characteristics of this multi-stakeholder committee.

\section{CONCLUSION}

Creating an international Multi-stakeholder Committee on DSI that can contribute to the development of a coordinated governance mechanism for the entire ABS framework would be an important step forward. This new transversal Committee would aim at improving dialogue between science, policymakers and stakeholders from several different forums, to provide concrete options for normative solutions. Adding "another" committee might feel redundant given the already existing process mentioned here and would surely not be sufficient for solving all the ABS issues. But we strongly believe that given the complexity and technicality of the DSI controversy, a multi-disciplinary effort is needed to try working towards a coherent, workable solution for the future of the ABS framework. The use and commercial applications of DSI will continue to increase in the near future, especially following major sequencing projects like the Earth Biogenome project (Lewin et al., 2018). Therefore, we call for all stakeholders to actively support the establishment ofand contribute to-this new forum, to build a fair and sustainable governance mechanism for DSI. Setting up more consistent and inclusive policies for DSI across areas will allow to focus more attention to tackling the global challenges of biodiversity loss, food insecurity, pandemic risk and climate change we are facing. 


\section{AUTHORS' CONRIBUTIONS}

SA and CF contributed equally to this work. SA and CF design the concept, and all co-authors contributed to the paper. Except for the two corresponding authors, the names are listed by alphabetic order.

\section{ACKNOWLEDGEMENTS}

The views and opinions expressed in this article are those of the authors and do not necessarily reflect the official policies or positions of their affiliated institutions. This work was supported by the Swiss National Science Foundation (\#31003A_172977) and the Research Foundation (FWO) Flanders (grant $n^{\circ} 12 \times 8318 N$ ).

\section{CONFLICT OF INTERESTS}

$\mathrm{MJ}$ is a founder of, shareholder in and consultant to GyreOx Therapeutics, a company that uses DSI to engineer enzymes to create complex molecules to treat human disease.

\section{ORCID}

Sylvain Aubry (iD https://orcid.org/0000-0002-7598-3609 Christine Frison (iD https://orcid.org/0000-0002-0539-2627 Emile Frison (iD https://orcid.org/0000-0003-2220-3100 Marcel Jaspars (iD https://orcid.org/0000-0002-2426-6028 Muriel Rabone (iD https://orcid.org/0000-0002-8351-2313 Aysegul Sirakaya iD https://orcid.org/0000-0003-3330-1750 Devanshi Saxena iD https://orcid.org/0000-0003-3830-1258

\section{REFERENCES}

Aubry, S. (2019). The future of digital sequence information for plant genetic resources for food and agriculture. Frontiers in Plant Science, 10, 1-10. https://doi.org/10.3389/fpls.2019.01046

Belanger, J., \& Pilling, D. (2019). The state of the world's biodiversity for food and agriculture. http://www.fao.org/state-of-biodiversity-forfood-agriculture/en/

Blasiak, R., Wynberg, R., Grorud-Colvert, K., Thambisetty, S., Bandarra, N. M., Canário, A. V. M., da Silva, J., Duarte, C. M., Jaspars, M., Rogers, A. et al (2020). The ocean genome and future prospects for conservation and equity. Nature Sustainability, 3, 588-596. https:// doi.org/10.1038/s41893-020-0522-9

Boesch, D. F. (1999). The role of science in ocean governance. Ecological Economics, 31(2), 189-198.

Bond, M. R., \& Scott, D. (2020). Digital biopiracy and the (dis)assembling of the Nagoya Protocol. Geoforum, 117, 24-32. https://doi. org/10.1016/j.geoforum.2020.09.001

Cabrera Medaglia, J. (2020). Digital Sequence Information (DSI) and benefit-sharing arising from its use: An unfinished discussion. GRUR International, 69, 565-566. https://doi.org/10.1093/grurint/ ikaa057

Cabrera Medaglia, J., \& Perron-Welch, F. (2019). The benefit-sharing principle in international law. Journal of Intellectual Property Law \& Practice, 14, 62-76. https://doi.org/10.1093/jiplp/jpy162

CBD. (1992). Convention on biological diversity. http://www.CBD.int/

CBD. (2019). CBD ATHEG studies on Digital Sequence Informations. https://www.CBD.int/meetings/DSI-AHTEG-2020-01

CFS. (2017). The global strategic framework for food security and nutrition. http://www.fao.org/cfs/home/products/onlinegsf/en/

CFS. (2020). CFS website. http://www.fao.org/cfs/home/about/en/

De Schutter, O. (2013). The reform of the committee on world food security: The quest for coherence in global governance. https://cridho.
uclouvain.be/documents/Working.Papers/CRIDHO-WP-2013-8ODeSchutter-CFS-GolbalGovernance.pdf

Deplazes-Zemp, A., Abiven, S., Schaber, P., Schaepman, M., SchaepmanStrub, G., Schmid, B., Shimizu, K. K., \& Altermatt, F. (2018). The Nagoya Protocol could backfire on the Global South. Nature Ecology \& Evolution, 2, 917-919. https://doi.org/10.1038/s41559-018-0561-z

dos S. Ribeiro, C., Koopmans, M. P., \& Haringhuizen, G. B. (2018). Threats to timely sharing of pathogen sequence data. Science, 362, 404-406. https://doi.org/10.1126/science.aau5229

ENB. (2019). Earth negotiations bulletin (Vol. 9, No. 740). https://enb.iisd. org/vol09/enb09740e.html

Finkelstein, L. S. (1995). What is global governance? Global Governance: A Review of Multilateralism and International Organizations, 1(3), 367372. https://doi.org/10.1163/19426720-001-03-90000007

Frison, C. (2018). Redesigning the global seed commons law and policy for agrobiodiversity and food security. Routledge.

Frison, C. (2021). Biodiversity. In K. De Feyter, S. De Moerloose, \& G. Türkelli (Eds.), Law \& development encyclopaedia (pp. 1-32). Edward Elgar.

Halewood, M., Lopez Noriega, I., Ellis, D., Roa, C., Rouard, M., \& Sackville, H. R. (2018). Using genomic sequence information to increase conservation and sustainable use of crop diversity and benefitsharing. Biopreservation and Biobanking, 16, 368-376. https://doi. org/10.1089/bio.2018.0043

Herz, M. (2018). Formal and informal groups. In G. W. Weiss \& S. Daws (Eds.), The Oxford Hanbook on the United Nations (pp. 332-345). Oxford University Press.

Hess, C., \& Ostrom, E. (2003). Ideas, artifacts, and facilities: Information as a common-pool resource. Law and Contemporary Problems, 66, 111-146.

Humphries, F., Gottlieb, H. M., Laird, S., Wynberg, R., Lawson, C., Rourke, M., Tvedt, M. W., Oliva, M. J., \& Jaspars, M. (2020). A tiered approach to the marine genetic resource governance framework under the proposed UNCLOS agreement for biodiversity beyond national jurisdiction (BBNJ). Marine Policy, 122, 103910. https://doi.org/10.1016/j. marpol.2020.103910

IPBES. (2019). Global assessment report on biodiversity and ecosystem services of the Intergovernmental Science-Policy Platform on Biodiversity and Ecosystem Services. https://ipbes.net/global-asses sment

ITPGRFA. (2004). International treaty on plant genetic resources for food of the food and agriculture organization. www.fao.org/3rd/ai0510e.pdf\%0A\%0A

Jungcurt, S. (2008). Institutional interplay in international environmental governance: Policy interdependence and strategic interaction in the regime complex on plant genetic resources for food and agriculture. Shaker Verlag.

Laird, S., Wynberg, R., Rourke, M., Humphries, F., Muller, M. R., \& Lawson, C. (2020). Rethink the expansion of access and benefit sharing. Science, 367, 1200-1202. https://doi.org/10.1126/science.aba9609

Lawson, C., Burton, H., \& Humphries, F. (2018). The important place of information in the evolving legal and policy framework for the conservation and sustainable use of the world's plant genetic resources for food and agriculture. European Intellectual Property Review, 40.

Leonelli, S. (2014). Data interpretation in the digital age. Perspectives on Science, 22, 397-417. https://doi.org/10.1162/POSC_a_00140

Lewin, H. A., Robinson, G. E., Kress, W. J., Baker, W. J., Coddington, J., Crandall, K. A., Durbin, R., Edwards, S. V., Forest, F., Gilbert, M. T. P., Goldstein, M. M., Grigoriev, I. V., Hackett, K. J., Haussler, D., Jarvis, E. D., Johnson, W. E., Patrinos, A., Richards, S., Castilla-Rubio, J. C., ... Zhang, G. (2018). Earth BioGenome Project: Sequencing life for the future of life. Proceedings of the National Academy of Sciences of the United States of America, 115, 4325-4333. https://doi.org/10.1073/ pnas.1720115115 
Mehrabi, Z., McDowell, M. J., Ricciardi, V., Levers, C., Martinez, J. D. Mehrabi, N., Wittman, H., Ramankutty, N., \& Jarvis, A. (2020). The global divide in data-driven farming. Nature Sustainability. https://doi. org/10.1038/s41893-020-00631-0

Morgera, E. (2016). The need for an international legal concept of fair and equitable benefit sharing. European Journal of International Law, 27, 353-383. https://doi.org/10.1093/ejil/chw014

Morgera, E. (2017). Fair and equitable benefit-sharing: History, normative content and status in International Law. In E. Orlando \& L. Krämer (Eds.), Encyclopedia of environmental law (pp. 1-15). Principles of Environmental Law.

Morgera, E., Switzer, S., \& Geelhoed, M. (2020). Study for the european commission on 'possible ways to address digital sequence information - legal and policy aspects'. Consultancy project conducted for the European Commission (pp. 1-74). Strathclyde Centre for Environmental.

Oberthür, S., \& Pożarowska, J. (2013). Managing institutional complexity and fragmentation: The Nagoya protocol and the global governance of genetic resources. Global Environmental Politics, 13, 100-118. https://doi.org/10.1162/GLEP_a_00185

Peres, S. (2016). Saving the gene pool for the future: Seed banks as archives. Studies in History of Biological and Biomedical Sciences, 55, $96-$ 104. https://doi.org/10.1016/j.shpsc.2015.09.002

Pistorius, R., \& van Wijk, J. (1999). The exploitation of plant genetic information: Political strategies in crop development. CABI Publishing.

Rourke, M. (2019). Access by design, benefits if convenient: A closer look at the pandemic influenza preparedness framework's standard material transfer agreements. The Millbank Quarterly, 97(1), 91-112. https://doi.org/10.1111/1468-0009.12364

Sirakaya, A. (2019). Balanced options for access and benefit-sharing: stakeholder insights on provider country legislation. Frontiers in Plant Science, 10, 1-15. https://doi.org/10.3389/fpls.2019.01175
Stephens, Z. D., Lee, S. Y., Faghri, F., Campbell, R. H., Zhai, C., Efron, M. J., Iyer, R., Schatz, M. C., Sinha, S., \& Robinson, G. E. (2015). Big data: Astronomical or genomical? PLoS Biology, 13, e1002195. https://doi. org/10.1371/journal.pbio.1002195

Stoll, P. (2009). Access to GRs and benefit sharing: Underlying concepts and the idea of justice. In G. Winter \& E. Kamau (Eds.), Genetic resources, traditional knowledge and the law: Solutions for access and benefit sharing (pp. 3-18). Routledge.

Thacker, E. (2005). The global genome. The MIT Press.

UNESCO. (1998). Universal declaration on the human genome and human rights. https://www.ohchr.org/

UNESCO. (2003). International declaration on human genetic data. https://unesdoc.unesco.org/ark:/48223/pf0000133171.page $=45$

Weiss, T. G. (2000). Governance, good governance and global governance: Conceptual and actual challenges. Third World Quarterly, 21(5), 795-814. https://doi.org/10.1080/713701075

WILDSI. (2020). WILDSI white paper. https://www.dsmz.de/filea dmin/user_upload/Collection_allg/Final_WiLDSI_White_Paper_ Oct7_2020.pdf

WHO (2011). Pandemic influenza preparedness Framework for the sharing of influenza viruses and access to vaccines and other benefits. https://www.who.int/influenza/resources/pip framework/en/

How to cite this article: Aubry S, Frison C, Medaglia JC, et al. Bringing access and benefit sharing into the digital age.

Plants, People, Planet. 2022;4:5-12. https://doi.org/10.1002/

ppp3.10186 